\title{
ENSINO DAS LITERATURAS DE LÍNGUA PORTUGUESA COMO ESTRATÉGIAS DE LEITURA
}

\author{
TEACHING PORTUGUESE LITERATURE AS READING STRATEGIES
}

\author{
Norma Sueli Rosa LIMA \\ Universidade do Estado do Rio de Janeiro \\ norma.lima@uerj.br
}

Resumo: $O$ artigo propõe-se a examinar o percurso do ensino das Literaturas de Língua Portuguesa, no Brasil, a partir dos marcos de exclusão e de inclusão sociais, na perspectiva da abordagem da leitura (ZILBERMAN) e da concepção de língua enquanto linguagem, como motivações para este aprendizado. Por isso, diante dos contextos que evidenciam a expressão monológica (LUCHESI) ao invés da múltipla (BAKHTIN), percebe-se o projeto de associar o ensino à "missão civilizatória" (STAROBINSKI), que as Literaturas evidenciam e denunciam. Verifica-se, igualmente, o fato de que o acesso não veio acompanhado pela equidade, do mesmo modo que os espaços destinados à Literatura (e à leitura), na sociedade, vem cada vez mais sendo desprestigiados. Discorre sobre reflexões e metodologias que auxiliem professores e alunos a fortalecerem práticas para que a presença literária se torne realidade não somente no cotidiano escolar, mas como experiência cotidiana. Conclui que pensar sobre a disciplina Literatura é ponderar sobre a sua finalidade, desde o momento em que foi inserida no currículo como exemplo de bom vernáculo que deveria ser copiado para o aperfeiçoamento da Língua Portuguesa, como quando ficou restrita, depois da Lei 5.692/71, somente no antigo segundo grau, mesmo assim destinada a estudantes que fariam vestibular. Modernamente, as ponderações acercas do ensino da Literatura abarcam experiências da fruição estética e/ou humanizadoras (CANDIDO).

Palavras-chave: Ensino. Literaturas de Língua Portuguesa. Linguagem. Leitura.

\begin{abstract}
The article discusses the trajetory of Portuguese Language and Literature teaching in Brazil, from the social exclusion frameworks of access to school and inclusion strategies, the perspectives of the approach to reading (ZILBERMAN) and the conception of language as language, as motivations for (LUCHESI) and polyphony (BAKHTIN), as an integral part of a "civilization mission" (STAROBINSKI), which Literatures evidence and denounce (CANDIDO). In the present, to realize both the impasses and the challenges for the use of literary texts, in elementary and middle schools. We present a study of the trajectory of Portuguese language teaching and its literatures, from its historical, political and cultural contexts, which shows how this practice approached or was in conflict with the idea of a school built as a restricted space to the usufruct of privileged segments. If, for a long time, access to education was not facilitated, we now find that being a reality for almost the entire Brazilian population has not brought equity. In this way, we understand that it is necessary for teachers to understand the phenomena of the language with broader horizons,
\end{abstract}


reflecting on their use in society, in order to equip students to act for the construction of a new discourse in which they act as protagonists.

Keywords: Teaching. Literatures of Portuguese Language. Language. Reading.

\section{Algumas reflexões}

O exame da trajetória do ensino de Língua Portuguesa e de suas Literaturas, a partir dos seus contextos histórico, político e cultural, evidencia o quanto esta prática se aproximou, ou esteve em conflito, com a ideia de escola construída como espaço restrito ao usufruto de segmentos privilegiados. Desde a fase do Brasil Colônia, quando havia uma "Língua Geral" (recolhida das expressões orais de algumas etnias nativas) e a Língua Portuguesa ainda não havia assumido estatuto de idioma vernáculo a ser ensinado, nem a Literatura Brasileira se configurava como símbolo da nação, o que só aconteceria após a Independência, a concepção hegemônica pretendeu eleger para o currículo uma variante dentre as várias línguas aqui faladas, em detrimento das demais.

A homogeneização linguística realizada pelos jesuítas, por meio da gramatização da 'língua geral', cancelava tendencialmente a diversidade e a riqueza étnicas e linguísticas. Essa simplificação aparece nitidamente na 'língua geral' jesuítica, constituída a partir do 'tupinambá', mas com o qual ela apresenta diferenças de ordem gramatical, devidas sobretudo ao fato de que sua descrição e gramatização realizou-se a partir do modelo latino. (CARBONI; MAESTRI, 2003, p. 19-20)

Após a expulsão dos religiosos pelo Marquês de Pombal em 1757, as práticas docentes se transformaram em laicas, substituindo a antiga ação educativa por outra, de base racionalista, mas sem abarcar no novo projeto os índios e os africanos escravizados (o tráfico se iniciara no século XVI). "As dificuldades surgidas por parte dos índios reduzem-se (...) às escassas posses financeiras (...) a contribuírem com o limitado estipendio dos mestres da escola" (ANDRADE, 1978, p. 11). Foram incessantes, a partir daí, a discriminação e a subalternização do tupi: “(...) um governador do Maranhão recomendava aos jesuítas que aplicassem palmatoadas aos jovens nativos que falassem aquela língua". (CARBONI; MAESTRI, 2003, p. 27). A ideia da formação de professores, através de escolas especializadas, era inexistente no Brasil do século XVIII e mesmo a partir de 1870 somente às mulheres era permitido lecionar. (LAJOLO; ZILBERMAN, 1999, p. 166). 
Ao africano, que praticava coloquialmente falares mandinga, jeje, quimbundo, umbundo, entre outros, não se cogitou fornecer o ensino oficial da Língua Portuguesa, a qual ele precisou aprender "de ouvido" para cumprir as ordens dos "seus senhores". Cativos, seus nomes eram trocados por outros de origem ocidental, pois, apagando os laços étnicos, facilitava-se a destruição do ambiente plurilinguístico, para a manutenção de uma única variante

O aprendizado do português, que se faz o idioma vernáculo dos escravos, incapazes de se comunicar entre eles nas suas línguas respectivas, não pode ser absorvido muito depressa e a língua torna-se verdadeira barreira entre os recém-chegados e os outros. (...) Dizem-se crioulos os escravos nascidos no Brasil e que, logicamente, falam realmente o português (...) enquanto o africano boçal, isto é, nascido bem longe, falando mal a língua do branco. (...) Em geral, o senhor não se dá conta do que pode representar o acervo cultural africano e com frequência julga estar diante de um "selvagem" que lhe cabe educar em todos os domínios.

(MATTOSO, 1990, p. 105-106)

A Língua Portuguesa conviverá com outros falares de contato (indígenas e africanos) nos contextos de oralidade, formando espontaneamente o Português brasileiro, expressão de uma maioria que não frequentava as escolas, local exclusivo para os segmentos abastados.

É certamente no entrecruzar-se de variantes localizadas menos ou mais interferidas por marcas indígenas e/ou africanas, de variantes mais gerais menos ou mais africanizadas ou menos ou mais aportuguesadas que se definem e emergem os traços característicos do português brasileiro, língua nacional. (SILVA, 2004, p. 22)

Embora o objetivo aqui não seja investigar a formação da nossa língua mediante as contribuições indígena e africana para a existência de uma variante distinta da instituída como a fala oficial do Brasil, é importante perceber as colaborações destas polifonias para o mapeamento da história do ensino de literaturas, as quais se expressam através dela. O Português brasileiro é herança das linguagens utilizadas por populações massacradas em suas línguas naturais, quando, após a Reforma Pombalina "o sagrado da civilização toma o lugar do sagrado da religião" e ensinar o novo idioma aos índios equivaleria à missão de "civilizar os indivíduos, suas maneiras, sua linguagem." (STAROBINSKI, 2011, p. 33-34).

O fato de, igualmente, os falares africanos não sobreviverem fora de seus espaços de resistência (como os das suas religiões) se deve, principalmente, ao fato de terem sido forçados ao processo de branqueamento a utilizarem a língua oficial única em vigência - a fim de obterem alguma "aceitação social": "o alto grau da 
mestiçagem e as possibilidades de inserção social dos mestiços na sociedade brasileira podem ser (...) fatores de inibição de eventuais processos de crioulização do português" (LUCCHESI, 2008, p. 167). Excluídas dos bancos escolares, estas vozes terminaram construindo uma teia enunciativa de fios heterogêneos, que misturavam a língua portuguesa às línguas naturais. Posteriormente, quando os falantes de variantes mestiças passaram a frequentar os estabelecimentos de ensino, nos quais a aprendizagem se processava na perspectiva exclusiva da variante culta, tiveram seus discursos contributivos avaliados como "erro", porque foram considerados na perspectiva da "contaminação" prejudicial à pureza do texto vernáculo:

Para a civilização dos índios, a imposição da língua portuguesa, ao lado de outras medidas, como os casamentos mistos, era o fundamental. Já para as camadas urbanas letradas, era preciso mais, era preciso uma 'civilização da linguagem' e é para esta tarefa que vai se voltar a reforma dos estudos menores com a criação das aulas régias. (ALMEIDA, 2008, p. 72)

Se o estudo das letras entrara em decadência ao ir para as mãos dos jesuítas, Portugal ao mesmo tempo em que se esforçava para ficar próximo à llustração da França, já se apresentava em declínio enquanto potência marítima. Procurava, agora, privilegiar a cultura das ciências, pois o ensino religioso interrompera a tradição do Humanismo e precisava ser superado porque "o caminho escolhido pelos reformadores portugueses foi o de uma reforma literária (...) com suas regras, abarcando tanto as gramáticas portuguesa e latina, como os estudos da retórica e da poética". (ALMEIDA, 2008, p. 74).

No século seguinte, o Brasil tornou-se independente e, ao promulgar a sua primeira Constituição, determinou que a formação escolar devesse ser acessível, como previa o Artigo 179, nos parágrafos XXXII e XXXIII: “A Instrucção primaria, e gratuita a todos os Cidadãos. Collegios, e Universidades, aonde serão ensinados os elementos das Sciencias, Bellas Letras, e Artes" (BRASIL. 1824). Por volta de 1850, já na ambiência do Segundo Império de Dom Pedro II, a formação do Instituto Histórico e Geográfico Brasileiro congregou as elites econômica e artística, "favorecendo a pesquisa literária, estimulando a via intelectual e funcionando como um elo entre estas e os meios oficiais." (SCHWARCZ, 1998, p. 126), além de fornecer à Língua Portuguesa característica de "unidade nacional". Através do estímulo e do auxílio a poetas, músicos, pintores e cientistas, D. Pedro II e um restrito grupo privilegiado da 
Corte se preocuparam em registrar e perpetuar uma certa memória, criada como legítima da nação brasileira: os historiadores cuidavam da tradição dos heróis nacionais, os pintores enalteciam a paisagem e os literatos imprimiam tipos que a simbolizassem. O Romantismo atuou com o projeto de gerar à manifestação literária a especificidade de um jovem país que se opunha aos cânones da mãe pátria, idealizando o indígena distanciado dos centros urbanos, praticamente dizimado, porém eleito como herói em seus romances e poemas. Essa proposta (oriunda do Rio de Janeiro e projetada como nacional) recorreu, inclusive, à língua geral para a composição do léxico nativo desses textos.

O Colégio Pedro II assumiu os parâmetros do ensino de Língua e de Literatura indicativos do pertencimento a uma elite (SCHWARCZ, 1998, p. 150), quando a taxa de alfabetizados não ia além dos $30 \%$. A reivindicação por uma política educacional se fará mais tarde, já no contexto do Brasil República, nos moldes de uma visão positivista, que associou o cientificismo e o racionalismo como posturas que se propagarão, também, na educação. Implantado em 1889, o novo Regime, contudo, manteve o modelo tradicional de aprendizagem, pouco ou nada acessível, "bacharelesco e dirigido aos representantes do poder rural que ambicionavam cargos na administração pública" (ZILBERMAN, 1988, p. 40). A relação entre os poderes dessa fase fica clara na analogia possível de se fazer entre o coronel - no interior do país - e o Bacharel - na área urbana - (BOMENY, 2001), ambos com poderes de mando, em diferentes esferas. Mais tarde, a Reforma de 1925 culminará na criação do Ministério da Educação e Cultura, setor até então inédito, que ficará responsável pelos rumos da educação brasileira.

De um lado, a tentativa de manutenção de ensino restrito, de outro, a pressão incessante dos grupos menos favorecidos para este acesso (pobres, negros e, também, mulheres). A Revolução de 1930 pareceu atender a algumas demandas de políticas públicas voltadas para o acesso à educação e embora a Escola Nova quando os intelectuais, como Florestan Fernandes, assumiram a missão de auxiliarem no desenvolvimento cultural do Brasil - tenha trazido a postura científica, enfatizando o pensamento indutivo e experimental, manteve a metodologia tradicional para o ensino de Língua Portuguesa e de Literatura, com "leitura e imitação dos clássicos" (ZILBERMAN, 1988, p. 68). No Ministério Capanema, a Reforma do Ensino de 1942 
forneceu a orientação clássica e humanista àqueles que não se enquadrassem para a formação profissional e técnica, destinada aos "humildes" que, apesar da origem, tinham conseguido ingressar na escola (BOMENY, 2001, p. 53).

Após o final da Segunda Guerra Mundial, foi crescente a demanda dos benefícios educativos a segmentos maiores da população, tendo sido substituída a preocupação em qualificar mão de obra para absorção nas indústrias pelo incentivo educacional a maiores participações políticas e sociais. Em meados do século XX, o espaço escolar convivia com distintas classes sociais, pois os centros urbanos passaram a receber segmentos da população rural em levas migratórias, na busca por melhores condições de vida, em função do processo de industrialização. período compreendido entre 1950 a 1964 percebeu aquele lugar também enquanto ação política, tendo como marcos, por exemplo, iniciativas como a Pedagogia da Libertação, de Paulo Freire, efervescência interrompida pelo Golpe Militar.

Avaliar estes e outros pressupostos é fundamental para a reflexão acerca dos atuais rumos do ensino das Literaturas de Língua Portuguesa, principalmente a partir da década de 90, quando a Lei de Diretrizes e Bases da Educação de 1996 substituiu a Reforma de 1971 e relacionou o ensino da gramática e da literatura com as concepções de Linguagem difundidas pelo tratamento não hegemônico atribuído a Mikhail Bakhtin (BRANDIST, 2006). Relacionando os gêneros (infindáveis) à oralidade (inumerável), Bakhtin aglutinou uma série de importantes referências sócio históricas para a compreensão dos seus surgimentos, ao pensar na formação dos enunciados, das enunciações (diversidade, escolha, intenção, interação, para citar alguns) e no caráter responsivo destas conclusibilidades:

Até hoje ainda existem na linguística ficções como "o ouvinte" e o "entendedor" (parceiros do "falante", do "fluxo único da fala", etc). Tais ficções dão uma noção absolutamente deturpada do processo complexo e amplamente ativo da comunicação discursiva. (...) sugere-se um esquema de processos ativos de discurso no falante e de respectivos processos passivos de recepção e compreensão do discurso no ouvinte. (...) Toda compreensão da fala viva, do enunciado vivo é de natureza ativamente responsiva (embora o grau desse ativismo seja bastante diverso); toda compreensão é prenhe de resposta, e nessa ou naquela forma a gera obrigatoriamente: o ouvinte se torna falante. (...) Os gêneros da complexa comunicação cultural, na maioria dos casos, foram concebidos precisamente para essa compreensão ativamente responsiva de efeito retardado. Tudo o que aqui dissemos refere-se igualmente, mutatis mutandis, ao discurso escrito e ao lido. (BAKHTIN, 2011, p. 271-2). 
Os anos 90 passaram a valorizar a educação como requisito para a democracia e à sociedade de mercado, a partir da percepção da ineficiência do sistema de ensino escolar em oferecer educação básica de qualidade, fato evidenciado pelos índices de

/.../ repetência, baixo desempenho em escrita (...). A sociedade da informação encontrou no país um sistema de ensino grande, mas incapaz de fornecer aos estudantes habilidades requeridas à competição e desempenho na sociedade urbana do conhecimento. (...) O grande problema hoje não é apenas correr atrás do que não foi feito, mas, principalmente, atender à demanda de indivíduos livres por uma sociedade democrática, competitiva e extremamente voltada ao consumo. (BOMENY, 2001, p. 66)

Ao pretender a integração de diferentes áreas do conhecimento, utilizando a linguagem como fio condutor destes diálogos, e trazer à cena, para o ensino de Língua e de Literatura, os gêneros discursivos e textuais, o pensamento bakhtiniano pareceu corresponder às expectativas das novas diretrizes para o ensino das Literaturas. Preconizado na "Lei de Diretrizes e Bases da Educação" de 1996 e nos "Parâmetros Curriculares Nacionais", lançados em 1998 e posteriormente complementados com os documentos direcionados para o Ensino Médio (2000 e 2006). Este conjunto de especificações se voltou à formação da cidadania, para uma aprendizagem na qual o aluno não fosse mero receptor do conhecimento, mas aquele que com ele interagisse, construindo-o.

Por isso o destaque fornecido aos gêneros textuais, a fim de tornar o estudante apto a participar da vida cultural em toda a sua extensão e a desfrutar de seus direitos civis, através do domínio de habilidades diversas que facilitassem este entendimento. Do mesmo modo, foi necessário o trabalho de aprendizado da língua conjugado com o texto (leitura) - não-literário e literário -, com a finalidade de unir as disciplinas de Língua e de Literatura, as quais, durante muito tempo - devido ao fato de a LDB de 1971 as ter separado, ficando a segunda restrita ao antigo segundo grau - foram abordadas através de visões dicotômicas.

Na década de 60 e início da de 70, (...) acreditava-se que valorizar a criatividade seria condição suficiente para desenvolver a eficiência da comunicação e expressão do aluno. Além disso, tais propostas se restringiam aos setores médios da sociedade, sem se dar conta das consequências profundas que a incorporação dos filhos das camadas pobres implicava. $O$ ensino de Língua Portuguesa orientado pela perspectiva gramatical ainda parecia adequado (...). A nova crítica do ensino de Língua Portuguesa, no entanto, só se estabeleceria mais consistentemente no início dos anos 80 , quando as pesquisas produzidas por uma linguística independente da tradição normativa e filológica e os estudos desenvolvidos em variação linguística e psicolinguística, entre outras, possibilitaram avanços nas áreas de educação e psicologia da aprendizagem (...).É neste período que ganha espaço um conjunto de teses que passam a ser incorporadas e admitidas, pelo menos em teoria, por instâncias públicas oficiais. A divulgação dessas teses desencadeou 
um esforço de revisão das práticas de ensino da língua, na direção de orientá-las para a ressignificação da noção de erro, para a admissão das variedades linguísticas próprias dos alunos, muitas delas marcadas pelo estigma social, e para a valorização das hipóteses linguísticas elaboradas pelos alunos no processo de reflexão sobre a linguagem e para o trabalho com textos reais." (BRASIL, 1998, p. 17-18).

Quase vinte anos após a publicação dos Parâmetros, pensar o percurso do ensino de Língua Portuguesa e de suas literaturas nos momentos que os antecederam, bem como atualizar reflexões a respeito de práticas próximas ou distanciadas deste documento, ainda que isso seja realizado aqui de forma sucinta, possivelmente poderá colaborar para os muitos desafios que envolvem, ainda nos nossos dias, a formação de professores, a qual, segundo recente documento do MEC, deve priorizar finalidades comuns a todas as disciplinas, para que os docentes privilegiem, nas relações com os alunos, os pressupostos de

/.../ desenvolver, aperfeiçoar, reconhecer e valorizar suas próprias qualidades, prezar e cultivar o convívio afetivo e social, fazer-se respeitar e promover o respeito ao outro, para que sejam apreciados sem discriminação por etnia, origem, idade, gênero, condição física ou social, convicções ou credos.

(BRASIL, 2015, p. 8)

\section{Das metodologias}

O lançamento de "O verdadeiro método de estudar" de Luiz Antônio Verney, em 1744 na Itália, foi uma das primeiras iniciativas de valorização da aprendizagem de língua vernácula (LAJOLO; ZILBERMAN, 1991, pág. 21); no Brasil, indagações sobre uma possível língua nacional começaram logo após a Independência, nas reflexões sobre as diferenças entre o nosso Português e o falado em Portugal. Em 1853, por exemplo, Brás Rubim criou o "Vocabulário brasileiro" para servir de complemento ao “Dicionário de Português", mas a primeira Gramática Nacional só foi publicada em 1830, seguindo a tradição de ser escrita por professores do Colégio Pedro II, cujo ensino era modelo para o país, sendo os currículos de Língua e de Literatura baseados na Retórica, na Poética e na Gramática. Não havia formação de instrutores, assim, os que lecionavam eram estudiosos do idioma nacional e da literatura, que também exerciam o magistério (SOARES, 1996, p. 159).

Em 1879, Pacheco Silva com a "Gramática Histórica da Língua Portuguesa" criou a orientação que serviria de parâmetro para os livros gramaticais posteriores: a propagação da unidade linguística com Portugal. Paralelamente, havia a concepção 
de que a literatura deveria identificar e difundir, em sua linguagem, a nação em que fora produzida. Além da leitura de textos clássicos, existia o estímulo para que os alunos produzissem composições que imitassem o estilo da variante culta utilizada pelos autores destas obras, as quais, nos livros gramaticais, também serviam de exemplificações (através de trechos) para os conceitos:

\begin{abstract}
Assim, nos contextos normativos ou descritivos de uma gramática, a presença de um verso, frase, período ou oração é uma espécie de atestado de qualidade conferido por especialista do estudo das regras da linguagem (e de suas teorias). Além disso, a linguagem contida nesses trechos - extraídos de obras da literatura vernácula - caracteriza um determinado modelo de correção que projeta uma exemplaridade passada sobre o presente e o futuro da língua.

(HENRIQUES, 2011, p. 104)
\end{abstract}

O fato de ter sido, durante muito tempo, encarada como "modelo de escrita" ou ainda enquanto disciplina preparatória para exames vestibulares, mais orientada para a historiografia, desvinculou a leitura da obra literária da sua função humanizadora, "isto é (...) a capacidade que ela tem de confirmar a humanidade do homem." (CANDIDO, 1972, p. 81) e da sua possibilidade de sonhar. Além destas, outras características podem ser acrescentadas à literatura: espaço de fruição estética e função educadora, que vai muito além de um ponto de vista estritamente pedagógico, sem ser uma espécie de "apêndice da instrução moral e cívica", pois

/.../ ela age com o impacto indiscriminado da própria vida e educa como ela, com altos e baixos, luzes e sombras. Daí as atitudes ambivalentes que suscita nos moralistas e nos educadores, ao mesmo tempo fascinados pela sua força humanizadora e temerosos da sua indiscriminada riqueza. E daí as duas atitudes tradicionais que eles desenvolveram: expulsá-la como fonte de perversão e subversão, ou tentar acomodá-la na bitola ideológica dos catecismos (...) (CANDIDO, 1972, p. 84)

A apreensão do texto literário como leitura é de fundamental importância para a percepção da pluralidade, marcada por sua inter-relação com diversos códigos (temáticos, linguísticos, etc) e da sua interação com outras áreas do conhecimento (intertextualidades, interdisciplinaridades, transversalidades, entre outros). (MARTINS, 2006, p. 88-89). É importante que o professor, na condição de leitor, faça com que o texto literário esteja ao alcance do aluno, pois provavelmente será o único ambiente no qual o aprendiz entrará em contato com ele, e, ao lhe possibilitar fornecer sentido ao que lê, o docente romperá com a visão do livro enquanto utilização exclusiva de e para o poder. 
Se outrora esteve a serviço das autoridades mundanas e religiosas (antes da invenção da imprensa), circula agora entre alunos-leitores de diferentes classes sociais, pois sempre houve a tentativa de se manter a leitura na esfera de uma burguesia, que dela poderia desfrutar com, por exemplo, móveis confortáveis, adaptados para esse prazer e roupas específicas para a tarefa: "O mobiliário para leitura foi complementado para as mulheres com a adequada liseuse, uma roupa de casa ou casaco quente, mas leve, para as viagens da fantasia." (WITTMANN, 1999, P. 150). Para os segmentos não abastados, a leitura era diversão distanciada do estímulo kantiano de autonomia, não concebida como possibilidade de independência e reflexão, fato que perdurou mesmo após a Segunda Revolução Industrial:

Os novos leitores do século XIX eram uma boa fonte de lucro, mas também provocavam ansiedade e inquietação entre as elites sociais. As revoluções de 1848 foram em parte vistas como resultado da disseminação de obras subversivas e socialistas, que alcançaram trabalhador urbano e um novo público no campo. (LYONS, 1999, p. 167)

Independente de não vivermos mais no contexto das leituras consideradas subversivas para o triunfo do capitalismo, ainda estamos no contexto do ato de ler como atitude revolucionária, pois através dele os indivíduos conseguem transpor uma ação aparentemente solitária a outra solidária, enquanto prática associada aos modos tradicionais de narrar e fundada na experiência oral, de sentido comunitário, como percebeu Walter Benjamin (1985). O acesso à escola e à leitura foi uma conquista dos segmentos à margem, que precisaram superar barreiras de gênero e de classe social:

\footnotetext{
A educação das meninas, em toda a Europa, estava em atraso em relação a dos meninos. Ao findar o século XVIII, apenas $9 \%$ dos alunos nas escolas estatais russas eram do sexo feminino e, em 1807, na Navarra espanhola, o número de escolas para meninos era o dobro das congêneres femininas. Na França, as primeiras escolas normais de professoras só foram fundadas em 1842. (...) Os jornais, com reportagens sobre eventos públicos, pertenciam geralmente ao domínio masculino; os romances, que tratavam da vida interior, eram parte da esfera privada à qual eram relegadas as mulheres burguesas do século XIX (...) Os estudiosos de história oral que entrevistaram mulheres acerca de seus hábitos de leitura antes de 1914 familiarizaram-se com algumas atitudes bem comuns. A resposta feminina mais frequente entre mulheres, ao recordarem as leituras de sua vida, consistia em lamentar que nunca tinham tido tempo para ler. (...) Descascar batatas, bordar, fazer pão e sabão eram tarefas que não deixavam tempo livre (...). Recordavam, ainda, que quando crianças, tinham medo de castigo se fossem apanhadas lendo. Os afazeres domésticos vinham em primeiro lugar, e admitir que liam equivalia a confessar que estavam negligenciando suas responsabilidades familiares de mulher. A imagem idealizada da boa dona de casa parecia incompatível com a leitura (...) A falta de luz era outro problema em lares da classe operária. As janelas nas casas da Inglaterra do início do século XIX eram poucas, e as velas eram caras. (LYONS, 1999, p. 167-193)
} 
As situações acima não eram exclusivas do ambiente europeu e podem ser transpostas para a realidade brasileira, com algumas adaptações, por serem ilustrativas da grande conquista que é a possibilidade de aproximar a leitura de obras literárias do maior número possível de indivíduos - ação da qual a escola é a principal (se não a única) difusora. A instituição pública - notadamente destinada às classes pobres, nos ensinos fundamental e médio - não é uma doação do Estado ao povo, tendo sido oriunda de uma progressiva e lenta conquista destas camadas pela democratização do saber. Do mesmo modo que, na universidade, os cursos de licenciatura devem dissolver a visão deturpada de que preparar os que atuarão nos ensinos fundamental e médio é algo diferente de formar os que terão perfil "acadêmico", como argutamente observou Magda Soares, já na década de 80 (2002, p. 18).

Se durante muito tempo o acesso à educação não foi facilitado, constatamos atualmente que, sendo realidade para quase toda a população brasileira, não trouxe com isso a equidade. A década de 80 alertou para o fracasso escolar, o qual a Lei de Diretrizes e Bases de 1971 não resolveu ao fornecer a "solução" de uma escola para os filhos da elite e outra para os dos trabalhadores, quando bifurcou, no segundo grau, dois currículos distintos: um direcionado à universidade (com matérias do núcleo comum, como a literatura) e outro voltado ao mercado de trabalho (sem as disciplinas que seriam avaliadas no exame vestibular, substituindo-as por outras, técnicas).

Importantes livros questionaram essa dicotomia, como "O texto na sala de aula", publicado em 1984 e organizado por João Wanderley Geraldi, que fez referência, entre outras inquietações, à divisão das disciplinas de Língua Portuguesa e de Literatura, que seguia os preceitos da LDB/71:

(...) relembrando que, no meu tempo de estudante de ginásio e colégio, literatura brasileira, literatura portuguesa e língua portuguesa faziam parte de uma disciplina denominada português. Aí se lia, aí se redigia, aí nos informavam dos saberes já existentes a respeito da literatura (especialmente a história literária, a retórica e a poética tradicionais) e da língua (a gramática normativa). Mas, apesar de reunidas numa mesma disciplina e na mesma figura do professor, a língua e a Literatura permaneciam como dois campos separados, didaticamente distribuídos em horários diferentes.

Hoje a separação se acentuou: da disciplina de comunicação e expressão, no primeiro grau, não faz parte a literatura - que só vai entrar no programa de segundo grau, entendida como história literária ou apresentação de autores e obras exigidos no vestibular. No primeiro grau, o que acontece é a entrada esporádica de um ou outro livro, ou de fragmentos, e o domínio dos chamados paradidáticos.

Ontem, como hoje, dificilmente conseguimos integrar o estudo da língua e o estudo da literatura. Sempre as aulas de língua tiveram a tendência a se concentrar na gramática, estudada 
abstratamente através de exemplos soltos, de frases pré-fabricadas sob medida para os fatos gramaticais a exemplificar ou a exercitar.

As vezes, pretendendo tornar a aula de gramática mais interessante (e duplamente útil, ilustrando os seus alunos) o professor trazia (ou traz) um texto literário para nele exercitar a busca de orações subordinadas ou de substantivos abstratos. Também era (e é) frequente a utilização de enunciados pescados cá e lá em contos, romances ou poemas de escritores consagrados para transformá-los, como a própria gramática o faz, em norma ou, ao contrário, em exemplos das exceções permitidas, porque provindas da pena de uma autoridade (o autor famoso). (LEITE, 2002, p. 17-18)

Contemporaneamente, os documentos oficiais do MEC, bem como uma série de outras publicações, têm se empenhado em estabelecer o texto como lugar privilegiado para este ensino em diálogo, sem, entretanto, utilizá-lo como mero pretexto para a busca de conteúdos gramaticais. Nessa perspectiva é que os "Parâmetros Curriculares do Ensino Médio" (2000) e as "Orientações Curriculares para o Ensino Médio" (2006) organizaram a sua proposta em função da não fragmentação no ensino destas disciplinas, prevendo-as direcionadas às capacidades do estudante de saber ler e interpretar conteúdos de linguagem verbal e não verbal, cabendo à escola promover a leitura para fazer chegar ao aprendiz o conteúdo literário, sem deixar de lado a que ele porventura realize fora da escola, ainda que não seja a dos livros indicados pelo cânone.

A atenção à essa pluralidade deve levar em conta o trabalho com os textos, não para a recolha de informações superficiais (tantos gramaticais, quanto temáticas) reforçamos, mas para que a sua recepção lhe atribua sentido, na observação dos modos como foram construídos e refletindo sobre essa construção.

O ensino da língua é, portanto, o ensino dos modos pelos quais os conteúdos ganham forma no texto, seja esse texto uma ode de Camões, um conto de Guimarães Rosa, um discurso de posse, uma página de horóscopo, um relatório, um modesto bilhete. (...) como os conteúdos que eles veiculam não são entidades abstratas e incorpóreas, os professores precisam estar atentos para as formas pelas quais os conteúdos são construídos (as marcas que identificam o ponto de vista do autor) (...) as formas de modalização, as estratégias de defesa de uma opinião ou tese, etc. (AZEREDO, 2007, p. 106).

Algumas indagações sempre se farão presentes por ocasião desta tarefa, dentre as quais: "Para que ensinar Literatura? Trata-se de aumentar a cultura dos alunos? Qual cultura? De formar leitores? Que Literatura ensinar a alunos de tão diferentes segmentos sociais e linguísticos?" (ROUXEL, 2013, p. 17-18).

É fundamental preparar o professor da Educação Infantil, Ensino Fundamental (anos iniciais e finais) e Ensino Médio para que, através do seu importante trabalho, 
também forme leitores literários, cabendo aos cursos de licenciatura inventariar os aspectos conceituais que norteiam a percepção dos licenciados sobre o que caracteriza a Literatura, bem como os seus lugares na trajetória da educação brasileira, sem esquecer das reflexões sobre as práticas que envolvem o ensino da linguagem, também postas nesse percurso.

Em um momento crucial, no qual o Ministério da Educação repensa o Currículo a partir de uma Base Nacional Comum, solicitando o auxílio e a participação de todos para as mudanças que se fazem necessárias, é importante assegurarmos os espaços já duramente conquistados, os quais estabeleçam o ensino distanciado de um modelo conservador.

A consciência da variação e das mudanças da língua e a valorização de todas as variedades como possuidoras de uma gramática eficaz e legítima são, portanto, determinantes para a forma de condução do trabalho voltado para os conhecimentos linguísticos pelo/a professor/a. A valorização das diferentes variedades da língua implica a valorização das diferentes identidades sociais. (BRASIL. 2015. P. 40-41)

Após este breve percurso a respeito do ensino das Literaturas de Língua Portuguesa, no Brasil, finalizamos o artigo ressaltando a importância de reflexões que auxiliem os professores a entenderem os fenômenos da Língua com horizontes mais amplos e a pensarem sobre o seu uso em sociedade, a fim de que instrumentalizem os alunos a atuarem pela construção de um novo discurso, nos quais atuem como protagonistas. Tudo isso sem esquecer que ensinar Literatura é pôr em diálogo com os homens um legado que, contemporâneo ou clássico, transmite às novas gerações "palavras que ajudam a viver melhor." (TODOROV, 2012, p. 94).

\section{Referências bibliográficas}

AZEVEDO, J. C. de. Ensino de português: fundamentos, percursos, objetos. Rio de Janeiro: Jorge Zahar Ed., 2007.

BAKHTIN, M. Estética da criação verbal. 6 $6^{\underline{a}}$ ed., São Paulo: Editora WMF Martins Fontes, 2011.

BENJAMIN, W. O narrador: considerações sobre a obra de Nikolai Leskov. In: Magia e técnica, arte e política: ensaios sobre literatura e história da cultura. São Paulo: Brasiliense, 1985.

BOMENY, H. Os intelectuais da educação. Rio de Janeiro: Jorge Zahar Editora, 2001. 
BRANDIST, C. Mikhail Bakhtin e os primórdios da sociolinguística soviética. In: CASTRO, G. de; FARACO, C. A.; TEZZA, C. Vinte ensaios sobre Mikhail Bakhtin. Petrópolis: Rio de Janeiro: Vozes, 2006.

CANDIDO, A. A literatura e a formação do homem. In: Ciência e cultura. São Paulo: Universidade de São Paulo, 1972.

CARBONI, F.; MAESTRI, M. A linguagem escravizada: língua, história, poder e luta de classes. São Paulo: Expressão Popular, 2003.

CASTRO, G. de; FARACO, C. A.; TEZZA, C. (Orgs). Vinte ensaios sobre Mikhail Bakhtin. Petrópolis, Rio de Janeiro: Vozes, 2006.

COSSON, R. Letramento literário: teoria e prática. $2^{\underline{a}}$ ed., São Paulo: Contexto, 2014

LEITE, L. C. de M. Gramática e literatura: desencontros e esperanças. In: GERALDI, J. W. (Org.). O texto na sala de aula. São Paulo: Ática, 2002.

HENRIQUES, C.C. Literatura como objeto de desejo: quando as visões linguístico-gramatical e teórico-literária se encontram. $2^{\mathrm{a}}$ ed., Rio de Janeiro: EdUERJ, 2011.

LAJOLO, M.; ZILBERMAN, R. A formação da leitura no Brasil. $3^{a}$ ed., São Paulo: Ática, 1999.

Brasil. São Paulo: Brasiliense, 1991.

A leitura rarefeita: livro e literatura no

LUCCHESI, D. Africanos, crioulos e a língua portuguesa. In: CARMO, L. do; LIMA, Ivana Stolze (Orgs). História social da língua nacional. Rio de Janeiro: Edições Casa de Ruy Barbosa, 2008, v. 1.

LYONS, M. Os novos leitores no século XIX: mulheres, crianças, operários. In: CAVALLO, G.; CHARTIER, R. (Orgs.). História da leitura no mundo ocidental. São Paulo: Ática, 1998, v. 2.

MARTINS, I. A literatura no ensino médio: quais os desafios do professor? In: BUNZEN, C.; MENDONÇA, M. (Orgs.) Português no ensino médio e formação do professor. São Paulo: Parábola Editorial, 2006.

MATTOSO, K. de Q. Ser escravo no Brasil. 3ª ed., São Paulo: Brasiliense, 2001.

ROUXEL, A. $O$ advento dos leitores reais. In: LANGLADE, G.; REZENDE, N. L.; ROUXEL, A. (Orgs.). Leitura subjetiva e ensino de literatura. São Paulo: Alameda, 2013. 
SCHWARCZ, L. M. As barbas do Imperador: D. Pedro II, um monarco nos trópicos. São Paulo: Companhia das Letras, 1998.

SILVA, R. V. M. e. Ensaios para uma sócio-história do Português brasileiro. São Paulo: Parábola Editorial, 2004.

SOARES, M. Linguagem e escola: uma perspectiva social. São Paulo: Ática, 2002.

Português na escola: história de uma disciplina escolar. In: BAGNO, M. Linguística da norma. São Paulo: Loyola, 2002.

STAROBINSKI, J. A palavra civilização. In: As máscaras da civilização: ensaios. São Paulo: Companhia das Letras, 2011.

TODOROV, T. A literatura em perigo. 4를. ed., Rio de Janeiro: Difel, 2012.

ZILBERMAN, R. A leitura e o ensino da literatura: democracia, educação e leitura; a escolha do texto; segundo grau; vestibular e literatura. São Paulo: Contexto, 1988.

WITTMANN, R. Existe uma revolução da leitura no final do século XVIII? In: CAVALLO, G.; CHARTIER, R. (Orgs.). História da leitura no mundo ocidental. São Paulo: Ática, 1998, v. 2.

BRASIL. Constituição política do Império do Brasil. Carta de Lei de 25 de março de 1824.

BRASIL. Lei de Diretrizes e Bases da Educação Nacional: no 9394/96. Brasília: 1996. Fixa as diretrizes e bases da educação nacional.

BRASIL. Lei 10.639/03 - Altera a Lei no 9.394, de 20 de dezembro de 1996, que estabelece as diretrizes e bases da educação nacional, para incluir no currículo oficial da Rede de Ensino a obrigatoriedade da temática "História e Cultura Afro-Brasileira", e dá outras providências.

BRASIL. Lei 11.645/08 - Altera a Lei no 9.394, de 20 de dezembro de 1996, modificada pela Lei no 10.639, de 9 de janeiro de 2003, que estabelece as diretrizes e bases da educação nacional, para incluir no currículo oficial da rede de ensino a obrigatoriedade da temática "História e Cultura Afro-Brasileira e Indígena".

BRASIL. SECRETARIA DA EDUCAÇÃO FUNDAMENTAL. Parâmetros Curriculares Nacionais: apresentação dos temas transversais, Língua Portuguesa, v. 2 Brasília: MEC/ SEF, 1997.

BRASIL. SECRETARIA DA EDUCAÇÃO DO ENSINO MÉDIO. Parâmetros Curriculares Nacionais Ensino Médio. Brasília: MEC/SEM, 2000. 
BRASIL. SECRETARIA DA EDUCAÇÃO DO ENSINO MÉDIO. Parâmetros Curriculares Nacionais: $O$ currículo da língua portuguesa e da literatura no ensino médio. 14a ed., Brasília, Distrito Federal: Editora FTD, 2006.

BRASIL. SECRETARIA DA EDUCAÇÃO BÁSICA. Currículo único nacional. Brasília, 2015. 